\title{
Assessing geographic and industry-related trends in bladder cancer in Ontario: A population-based study
}

Leandra Stringer ${ }^{1}$; Tina Luu Ly²; Nicolas Vanin Moreno ${ }^{1}$; Christopher Hewitt ${ }^{2}$; Michael Haan ${ }^{2}$; Nicholas Power ${ }^{1}$

${ }^{1}$ Division of Urology, Western University, London, ON, Canada; ${ }^{2}$ Department of Sociology, Western University, London, ON, Canada

Cite as: Stringer L, Ly TL, Morena NV, et al. Can Urol Assoc J 2021 September 24; Epub ahead of print. http://dx.doi.org/10.5489/cuaj.7263

Published online September 24, 2021

Corresponding author: Dr. Leandra Stringer, Division of Urology, Western University, London, ON, Canada; Leandra.stringer@1hsc.on.ca

$* * *$

\section{Abstract}

Introduction: Bladder cancer (BC) is the fifth most prevalent cancer in Canada, with 9000 Canadians diagnosed each year. ${ }^{1}$ While smoking is the most important risk factor, environmental and occupational carcinogens have been found to significantly contribute to BC rates. $^{2} \mathrm{As}$ Canada is highly reliant on natural resource industries, this study seeks to identify geographical and industry-related trends of BC rates in Ontario.

Methods: The 1991 and 2001 Canadian Census Health and Environment Cohort (CanCHEC; Statistics Canada) was used, along with individual years of Census data. Maps identifying hot and cold spots for BC within Ontario were generated, and the former were assessed for industry patterns between location and $\mathrm{BC}$ rates. Cox proportional hazards models were run for each age cohort to predict the likelihood of developing BC by industry of work.

Results: Significant geographical and industrial trends in BC rates were identified. For 19912001; hot spots included the Cochrane, Manitoulin, Parry Sound, and Sudbury (90\% confidence interval $[\mathrm{CI}]$ ), and Nipissing and Temiskaming (95\% CI) regions. Toronto and York were cold spots. Concurrently, metal $(\mathrm{p}=0.039)$, paper and publishing $(\mathrm{p}=0.0062)$, and wood and furniture $(\mathrm{p}<0.0001)$ industries had increased rates of BC. Notably, these industries had high employment density in our hot spot areas and low density in our cold spots. 
Conclusions: Significant geographical and industrial BC trends were found in Northern Ontario regions reliant on heavy employment in natural resource-based industries, such as forestry, agriculture, and wood/paper. These findings may inform future screening guidelines and aid in identifying individuals at risk of BC development.

\section{Introduction}

Bladder cancer (BC) is the fifth most prevalent cancer in Canada, with up to nine thousand diagnoses each year. ${ }^{1}$ Globally, BC is more prevalent in developed nations, affects more men than women, and demonstrates an age-related increase in risk-with new diagnoses commonly presenting in the seventh decade. ${ }^{2,3}$ The onset of BC presentation has led to the belief that a latency period exists between exposure to a carcinogen and disease manifestation. Recently, studies have attributed new cases to exposures occurring up to 40 years prior. ${ }^{4,5}$ In western nations, most BCs are of a urothelial cell histology, with squamous carcinoma, adenocarcinoma, and sarcomatoid tumors occurring less frequently. ${ }^{3,6}$ Given its high recurrence rate and treatment cost, BC represents a significant burden to the Canadian healthcare system. ${ }^{1,7}$

Exposure to environmental and occupational carcinogens have been found to be significant contributors to disease burden. ${ }^{2,6}$ A 2018 systematic review by Cumberbatch et al. ${ }^{2}$ attributed approximately 5-6\% of worldwide BC incidence to occupational carcinogen exposures. Amongst the industries studied, the rubber manufacturing, dye/textile, transportation, and service industry had the strongest association between long-term employment and development of BC. ${ }^{8-12}$ Further, individuals living near combustion, water treatment, mining, ${ }^{13,14}$ mechanical/car manufacturing establishments, ${ }^{15}$ power plants, ${ }^{16}$ and mining/textile plants ${ }^{14,17}$ were found to be at an increased risk, regardless of employment. This is postulated to be due to the run-off of waste products, which exposes nearby populations to aromatic amines, vehicle exhaust, heavy metals and arsenic_compounds known to increase the risk of urothelial cell carcinoma (UCC). ${ }^{3,6}$ In particular, the presence of arsenic in the drinking water of nearby communities, especially those reliant on well-water, has raised significant concern given the strong association between chronic arsenic ingestion and BC. . $^{3,18,19}$

Canada is highly reliant on the natural resource industry, including several smelters, mines, and pulp and paper plants that potentially deposit by-products like heavy metals and arsenic into the nearby environment. Despite the significant burden of BC, and the discovery of geographical trends in countries such as Spain, France, the US, and Japan, there is no literature that investigates the geographic distribution of BC in Ontario and its association with environmental exposures. Using the 1991 and 2001 Canadian Census Health and Environment 
Cohort (CanCHEC), this study seeks to identify geographical trends related to BC in Ontario, and whether these trends may be associated with a particular industry.

\section{Methods}

The 1991 and 2001 CanCHEC samples were derived from the long-form Census responses of the same years. ${ }^{20}$ Through CanCHEC, the Census responses are linked to administrative health data, including Cancer registries, vital statistics databases, and postal code information. The analytical sample consists of those with BC (site of tumor classified as 188, ICD-9, or C67, ICD-10), who were living in Ontario at the time of the Census.

The maps were generated using the Postal Code ${ }^{\mathrm{OM}}$ Conversion File, ${ }^{21,22}$ and 2011 census division (CD) boundaries (Figure 1). The total number of cases of BC for 1991 to 2001 and 2002 were divided by the total population across years in each $\mathrm{CD}$ to determine the annual rate. The responding average annual rates for each set of years were visualized using a Cartographic Boundary File. $^{23,24}$

Spatial clustering of the data was assessed with the $\mathrm{G}$ statistic. This statistic indicates in the study area contains hot spots (clusters of more bladder cancer instances than expected) or cold spots (clusters with fewer cases than expected). ${ }^{25}$ The G statistic is commonly used in geographic information system (GIS) packages. If the G statistic is significant, it indicates spatial clustering. If it is not significant, there is no spatial clustering. This analysis was conducted with an adjacent and corner-based spatial weight for each census division to examine concentrations of values in these areas. ${ }^{26}$ First, the global value at the provincial level was reported. Then, we selected the $\mathrm{Gi}^{*}$ statistic to locate and map hot/cold spots at the local or census division level. ${ }^{25-}$ 27

Individual Census years $(1991,1996,2001,2006)$ were used to measure the distribution of industries among the previously discussed hot and cold spots. Further, chi-square tests between industry of work and CD of residence were conducted. The industries were: agriculture, fishing/trapping, logging/forestry, mining, manufacturing, construction, transportation/storage, communication, wholesale trade, retail, finance, real estate, business, government, education, health, accommodation/food/beverage, other retired, and unemployed. Additionally, the distribution of manufacturing subsectors across CDs were investigated, due to known chemical exposures in manufacturing and its association with BC. All results were weighted and frequencies were rounded, as per Statistics Canada's guidelines.

Once the geographic and industry trends in BC were analysed, Cox proportional hazards models were used among the Census cohorts to identify associations between natural-resource industries and $\mathrm{BC}$ incidence. The first set of models used Manufacturing sub-sectors, which were found in Census data, to predict the likelihood of getting BC, while producing estimates for age groups 25-34, 35-44, 45-54, 55-64 and 65+. 
The next set of models were used to investigate the main areas of employment in the $\mathrm{BC}$ hot spots. The results of which indicated these to be: Agriculture, Logging/Forestry, Mining, Manufacturing, and those who were Retired/Unemployed. We then compared these groups to all other industries to develop an indication of the likelihood of developing BC by employment position. The chosen age groups for our estimates were 45-54, 55-64, and 65+ because BC is rare below the age of 45 and we did not want to dilute our data with outliers. All models control for gender.

\section{Results}

Overall, significant trends in rates of BC were identified in relation to geography and industry of employment. These rates are visualized cartographically in Figures 2 and 3 for the years 19912001 and 2002-2010, respectively. The population per census division for each census (1991, 1996, 2001, 2006 and 2011) were utilized and the difference between each set of 5 years was calculated. The difference was then divided by 5 to provide the annual increase or decrease in population by year for each census division. Based on annual rates for each year, the total population per year was calculated. Next, the populations per census division for each year were added together for the years 1991 to 2001 and 2002 to 2010. The total number of cases of BC for the same set of years was determined and divided by the calculated respective total populations per census division, providing the average annual rate for each set of years. These rates were then visualized using a Cartographic Boundary File. Due to their size, the rates were expressed in scientific notation. The map categories were classified in ArcGIS based on the natural groups in the data. This is a recognized standard mapping technique. ${ }^{24}$ Both maps use the same categorical breaks in the data for easy comparison (based on 1991-2001 results). The BC rates for 19912001 range from $5.63 \times 10^{-5}$ to $3.34 \times 10^{-4}$, and indicate the largest rates occur in Kawartha Lakes, and the Leeds and Grenville and Timiskaming aggregation. In contrast, the lowest rates are in Chatham-Kent, Peel, Prescott and Russell, and York regions (see Figure 2). Comparatively, BC rates for 2002-2010 range from $6.63 \times 10^{-5}$ to $2.46 \times 10^{-4}$ with the largest rates in the Algoma, Huron, Leeds and Grenville, Oxford, Renfrew and Stormont, and the Dundas and Glengarry regions. The lowest rates were found in Frontenac, and the Manitoulin, Parry Sound and Sudbury aggregations (see Figure 3). Our findings overall imply there was no significant spatial clustering of BC rates at the provincial level between 1991-2001 $(\mathrm{p}=0.882)$ or 2002-2010 ( $\mathrm{p}=0.445$ ) (Table 1, general G statistics).

When examining Figures 2 and 3 further, the $G$ results become significant at the local level. In 1991-2001, hot spots were indicated in the Cochrane (90\% confidence), Manitoulin, Parry Sound and Sudbury (90\% confidence), and Nipissing and Timiskaming (95\% confidence; Figure 2) regions. In 2002-2010, hot spots were the Middlesex County and Prince Edward County (90\% confidence), as well as Hastings (95\% confidence) regions. Alternatively, the regions of Peel and York, as well as Toronto, were cold spots (95\% and 99\% confidence, 
respectively) (Figure 3). Importantly, the Greater Toronto Area consistently reads as a cold spot across maps, whereas the hot spot pattern appears to vary both spatially and temporally. Thus, at the $\mathrm{CD}$ level, location does appear to have an impact on $\mathrm{BC}$ rates.

When examining Census data, both geographic and industrial trends in BC were identified. Among the respondents who were 55-64 years old in 1991, those who worked in metal ( $\mathrm{p}=0.039$, HR 1.19), paper and publishing ( $\mathrm{p}=0.0062$, HR1.29), and wood and furniture $(\mathrm{p}=<0.0001, \mathrm{HR} 1.84)$ manufacturing subsectors had increased rates of BC when compared to the machinery/transportation/electrical subsector. Importantly, the risk associated with wood/furniture employment was evident in 2001 as well $(\mathrm{p}=0.0008$, HR1.51). Following this trend, adults who were 65 and older in 1991 also experience higher rates of BC in this subsector ( $\mathrm{p}=0.093$, HR 1.4), which persisted into 2001 ( $\mathrm{p}=0.0015$, HR 2.42). Additionally, those working in metal ( $p=0.0075$, HR 2.02), and rubber/plastic/leather/textile ( $p=0.017$, HR1.89) in the 2001 cohort also indicated increased $\mathrm{BC}$ rates.

Moreover, among those aged 65 and older, additional manufacturing subsectors were identified as being at higher risk for BC. In 2001, these included food/beverage/tobacco industries ( $\mathrm{p}=<0.0001$, HR 3.38), as hot spot locations such as Manitoulin indicated high rates of employment in these areas. Overall, the highest rates of $\mathrm{BC}$ in the $65+$ population were found in food/beverage/tobacco, metal, rubber/plastic/leather/textile and wood/furniture industries. When looking at the 2006 census, we can see that the locations with the highest BC rates in 2002 (i.e., Hastings, Prince Edward and Middlesex) showed substantial proportions of employment in food/beverage/tobacco, machine/transportation, and retirement sectors.

In 1991-2001, the wood/furniture manufacturing industry had high levels of employment in high BC incident areas, such as Cochrane, Manitoulin, Parry Sound, Sudbury, Nipissing and Timiskaming. During the same period, there were comparatively lower levels of employment in these industries in Toronto and York, which are indicated cold spots (see map for 1991-2001). By 2002-2010, it is evident that these areas are no longer hot spots for BC. Alternatively, the paper and publishing manufacturing industry was found to have high levels of employment in our BC hot spots of Cochrane, Manitoulin, and Sudbury. Yet, when looking at these CDs in 2001, it becomes evident that, although this industry still has high employment rates compared to other manufacturing industries, the rates decreased in these locations. Importantly, these CDs in particular are no longer considered significant hot spots.

In relation to geography and $\mathrm{BC}$, analysis of industry and location identified that hot spots included regions with high population proportions employed in logging/forestry and wood/paper in the 1991 census, and fishing/logging/agriculture and forestry in the 2006 census.

\section{Discussion}

Overall, significant trends were identified between incidence of $\mathrm{BC}$ and both industry of work and geographical location in Ontario. Specifically, an analysis of the 1991 Census identified BC 
hot spots in the Manitoulin, Parry Sound and Sudbury aggregation, Nipissing and Timiskaming aggregation, and Cochrane region. Interestingly, these regions were also found to possess high rates of employment in industries associated with higher incidence of BC (i.e., wood/furniture, paper/publishing, and food/beverage/accommodation industries). Although direct causation cannot be deduced, these findings raise concern for the role of occupational exposures in increasing regional rates of $\mathrm{BC}$. Internationally, groups have identified increased $\mathrm{BC}$ risk in occupations involved in producing and processing paint, dye, metal, and petroleum products. ${ }^{13,14}$ Within Canada, a similar increase has been reported in metal workers. ${ }^{28}$

Further analysis of the data revealed not only an association between BC risk and occupation, but also to living proximity to certain industries. Hot spots included regions that possessed large populations working in or living near logging/forestry and wood/paper related industries in 1991 (e.g. Cochrane, Manitoulin, and Parry Sound and Sudbury), and regions with high occupational density in the agriculture/fishing/logging/forestry industries in 2006 (Middlesex, Prince Edward, and Hastings). In contrast, cold spots like Toronto and York had minimal employment in, and proximity to, the aforementioned industries. Thus, exposure to chemical and pollutant by-products potentially explains the discrepancy in BC rates between hot and cold zones. For example, exposure to agricultural products such as herbicides and organochlorine insecticides (DDT, heptachlor) have been found to be associated with an increased risk of $\mathrm{BC} .{ }^{29}$ Further, arsenic run-off produced by the paper and logging industry raises significant concern, given the strong association between chronic arsenic ingestion and BC. 3,18,19

Notably, certain hot spots in 1991 (e.g. Cochrane, Manitoulin and Sudbury; a region with prominent logging/forestry, and wood/paper industries) were no longer considered hot spots in 2001. If one infers that there may be an exposure portending to greater risk of BC, the dissipation of a hot spot may imply this exposure has been reduced. In Canada, the pulp and paper industry has seen drastic changes in labor conditions and chemical exposure in the workplace. Whereas pulp and paper employees were previously regularly exposed to asbestos, the chemical has been largely removed from the modern paper industry. ${ }^{30}$ Further, in 1992, stricter regulation on mill effluent reduced the discharge of chemicals from these factories into the environment, including chemicals associated with increased BC risk like chlorine byproducts ${ }^{31}$ and formaldehyde. ${ }^{30}$ It is possible that stricter chemical effluent reductions may have led to decreased chemical exposures for workers and local populations, subsequently leading to that area no longer being a hot spot many years later.

In future studies, we intend to investigate the presence of a temporal association related to $\mathrm{BC}$ development for people in these regions. We will assess if migration into and out of these communities affects the rate of BC. Our hope is to identify whether people who are born and spend their childhood in the community of interest and later move to a different location have the same risk of BC developing in their later years as those who remain in the community 
throughout the course of their lives. This will provide insight into whether early exposure to industry related effluent and pollution results in the same risk for BC as compared to long-term exposure.

A limitation of our study is that we were not able to control for smoking rates. Smoking is the most important risk factor for $\mathrm{BC},{ }^{32}$ however geographic data related to smoking was not available in the CanCHEC data. Despite this limitation, it is known that exposure to environmental and occupational carcinogens are significant contributors to the disease burden. ${ }^{2,6}$

\section{Conclusions}

There has been a substantial investigation on an international scale to identify occupation and environmental risks associated with BC. However, our study is the first to identify geographical and industry related risks for $\mathrm{BC}$ within Ontario specifically. Overall, we identify increased rates of $\mathrm{BC}$ in regions with high employment density in industries such as forestry, agriculture, wood/paper and accommodation/food/beverage. 


\section{References}

1. Bladder Cancer Canada. Bladder cancer facts. [cited 2020 Mar 13]. https://bladdercancercanada.org/en/bladder-cancer-facts/\#

2. Cumberbatch MGK, Jubber I, Black PC, et al. Epidemiology of bladder cancer: A systematic review and contemporary update of risk factors in 2018. Eur Urol 2018;74(6):784-95.

3. Letašiová S, Medved'ová A, Šovčíková A, et al. Bladder cancer, a review of the environmental risk factors. Environ Health 2012;11(1):S11.

4. Baris D, Waddell R, Beane Freeman LE, et al. Elevated bladder cancer in northern New England: The role of drinking water and arsenic. J Natl Cancer Inst 2016 [cited 2020 Apr 8];108(djw099). https://doi.org/10.1093/jnci/djw099.

5. Smith Norm D, Prasad Sandip M, Patel Amit R, et al. Bladder cancer mortality in the United States: A geographic and temporal analysis of socioeconomic and environmental factors. J Urol 2016;195(2):290-6.

6. Wong MCS, Fung FDH, Leung C, et al. The global epidemiology of bladder cancer: A joinpoint regression analysis of its incidence and mortality trends and projection. Sci Rep 2018;8(1):1129.

7. Jung YL, Tompa E, Longo C, et al. The economic burden of bladder cancer due to occupational exposure. J Occup and Environ Med 2018;60(3):217-25.

8. Case RA, Hosker ME. Tumour of the urinary bladder as an occupational disease in the rubber industry in England and Wales. Br J Prev Soc Med 1954;8(2):39-50.

9. Straif K, Weiland SK, Werner B, et al. Workplace risk factors for cancer in the German rubber industry: Part 2. Mortality from non-respiratory cancers. Occup Environ Med 1998;55(5):325.

10. Golka K, Wiese A, Assennato G, et al. Occupational exposure and urological cancer. World J Urol 2004;21(6):382-91.

11. Hadkhale K, MacLeod J, Demers PA, et al. Occupational variation in incidence of bladder cancer: A comparison of population-representative cohorts from Nordic countries and Canada. BMJ Open 2017;7(8):e016538.

12. Hadkhale K, Martinsen JI, Weiderpass E, et al. Occupational exposure to solvents and bladder cancer: A population-based case control study in Nordic countries. Int J Cancer 2017;140(8):1736-46.

13. García-Pérez J, Pollán M, Boldo E, et al. Mortality due to lung, laryngeal and bladder cancer in towns lying in the vicinity of combustion installations. Sci Total Environ 2009;407(8):2593-602.

14. Lopez-Abente G, Aragones N, Ramis R, et al. Municipal distribution of bladder cancer mortality in Spain: Possible role of mining and industry. BMC Public Health 2006;6(1):17.

15. Yaraaguchi N, Watanabe S, Okubo T, et al. Work-related bladder cancer risks in male Japanese workers: Estimation of attributable fraction and geographical correlation analysis. Jpn J Cancer Res 1991;82(6):624-31. 
16. Desbiolles A, Roudier C, Goria S, et al. Cancer incidence in adults living in the vicinity of nuclear power plants in France, based on data from the French Network of Cancer Registries. Int J Cancer 2018;142(5):899-909.

17. Rosas Rodríguez H. Estudio de la contaminación por metales pesados en la cuenca del Llobregat. Doctoral Thesis [Internet]. 2001. http://hdl.handle.net/2117/94296.

18. Cuzick J, Sasieni P, Evans S. Ingested arsenic, keratoses, and bladder cancer. Am J Epidemiol 1992;136(4):417-21.

19. Kurttio P, Pukkala E, Kahelin H, et al. Arsenic concentrations in well water and risk of bladder and kidney cancer in Finland. Environ Health Perspect 1999;107(9):705-10.

20. Statistics C. Canadian Census Health and Environment Cohorts (CanCHEC). 2020. https://www.statcan.gc.ca/eng/rdc/data/canchec.

21. Statistics C. Postal CodeOM Conversion File (PCCF), 2016. Statistics Canada Catalogue no. 92-154-X; 2016.

22. Statistics C. Postal CodeOM Conversion File (PCCF), Reference Guide, 2016.

23. Statistics C. Cartographic Boundary Files (CBF). 2011 Census. Ottawa, Canada; 2012.

24. Mitchell A. Chapter 3: Mapping the most and least. In: The ESRI Guide to GIS Analysis, Volume 1: Geographic Patterns and Relationships. 1st ed. Esri Press; 1999. p. 48.

25. Mitchell A. Chapter 4: Identifying clusters. Finding clusters of similar values. In: The ESRI Guide to GIS Analysis, Volume 2: Spatial Measurements and Statistics. 1st ed. Esri Press; 2005.

26. Getis A, Ord JK. The analysis of spatial association by use of distance statistics. Geogr Anal 1992;24(3):189-206.

27. Ord JK, Getis A. Local spatial autocorrelation statistics: Distributional issues and an application. Geogr Anal 1995;27(4):286-306.

28. Teschke K, Morgan MS, Checkoway H, et al. Surveillance of nasal and bladder cancer to locate sources of exposure to occupational carcinogens. Occup Environ Med 1997;54(6):443.

29. Koutros S, Silverman DT, Alavanja MC, et al. Occupational exposure to pesticides and bladder cancer risk. Int J Epidemiol 2015;45(3):792-805.

30. Soskolne CL, Sieswerda LE. Cancer risk associated with pulp and paper mills: a review of occupational and community epidemiology. Chronic Dis Can [Internet]. Supplement 2. 2010. https://www.canada.ca/en/public-health/services/reports-publications/healthpromotion-chronic-disease-prevention-canada-research-policy-practice/vol-29-no-22009/supplement/cancer-risk-associated-with-pulp-paper-mills-review-occupationalcommunity-epidemiology.html

31. Canadian Cancer Society. Risk factors for bladder cancer. [cited 2020 Apr 7]. https://www.cancer.ca/en/cancer-information/cancer-type/bladder/risks/?region=on.

32. National Institutes of Health. Smoking and Bladder Cancer. NIH Research Matters. 2011 Aug 29 [cited 2020 Jan 7]. https://www.nih.gov/news-events/nih-researchmatters/smoking-bladder-cancer. 


\section{Figures and Tables}

Fig. 1.

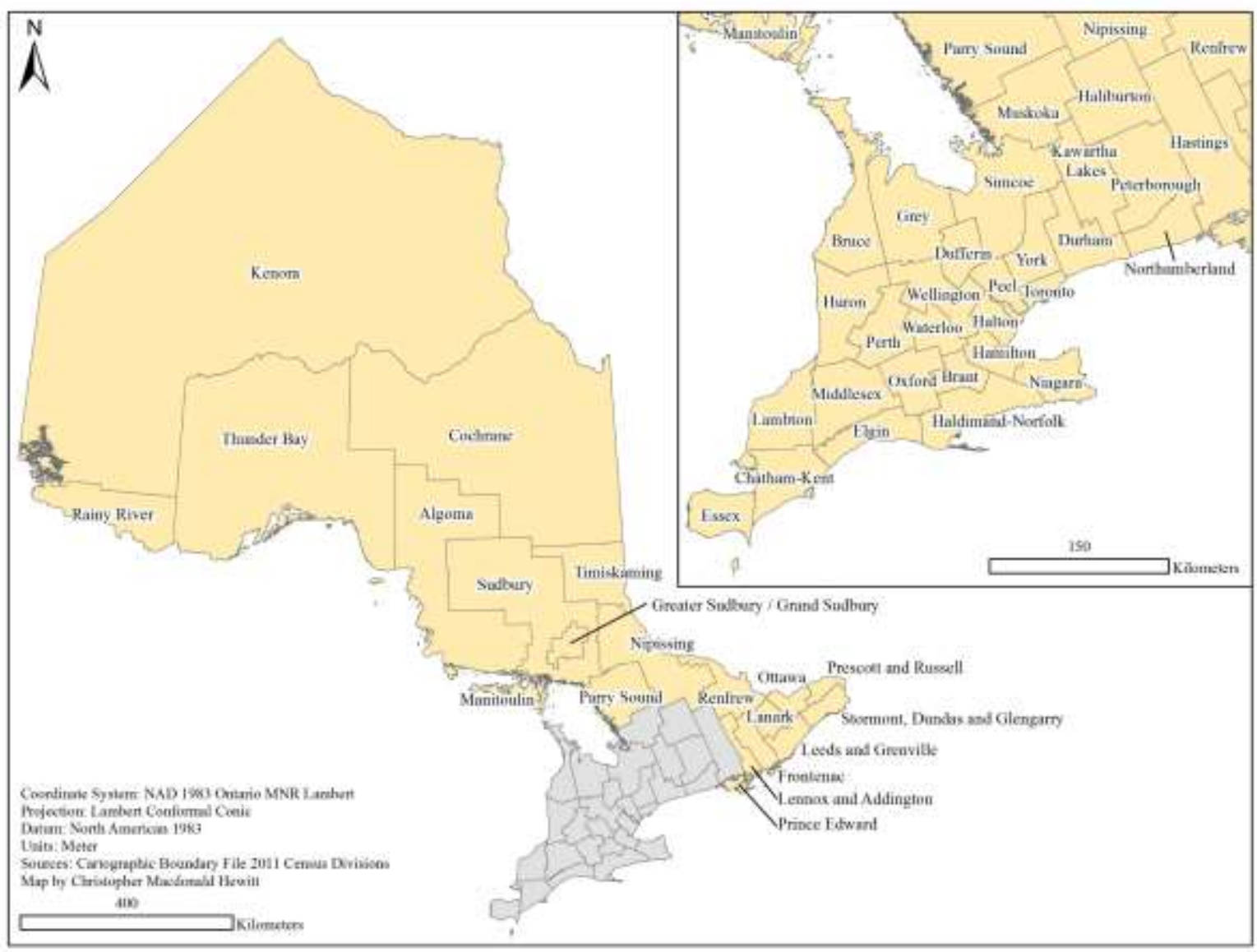


Fig. 2.
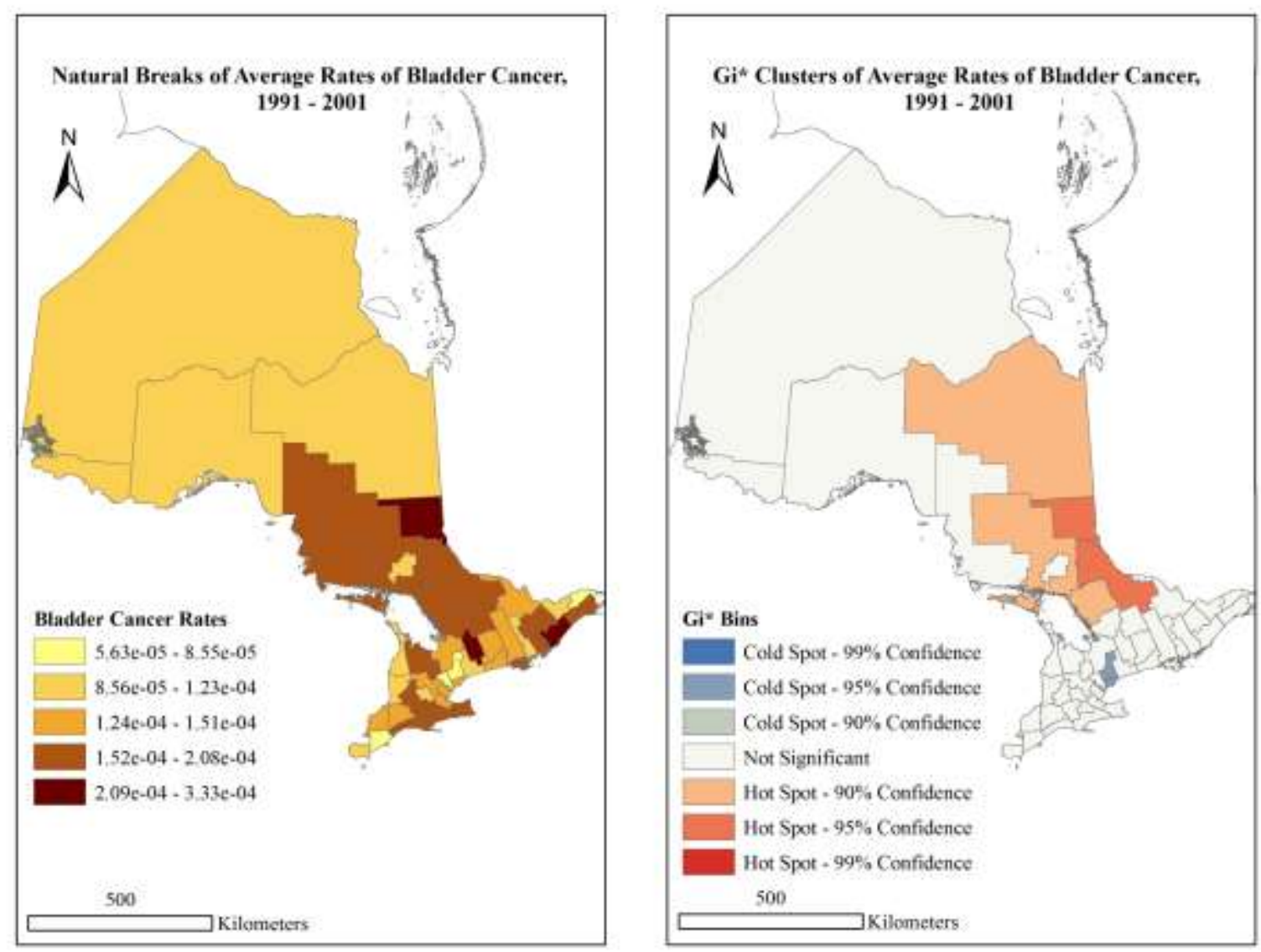
Fig. 3.
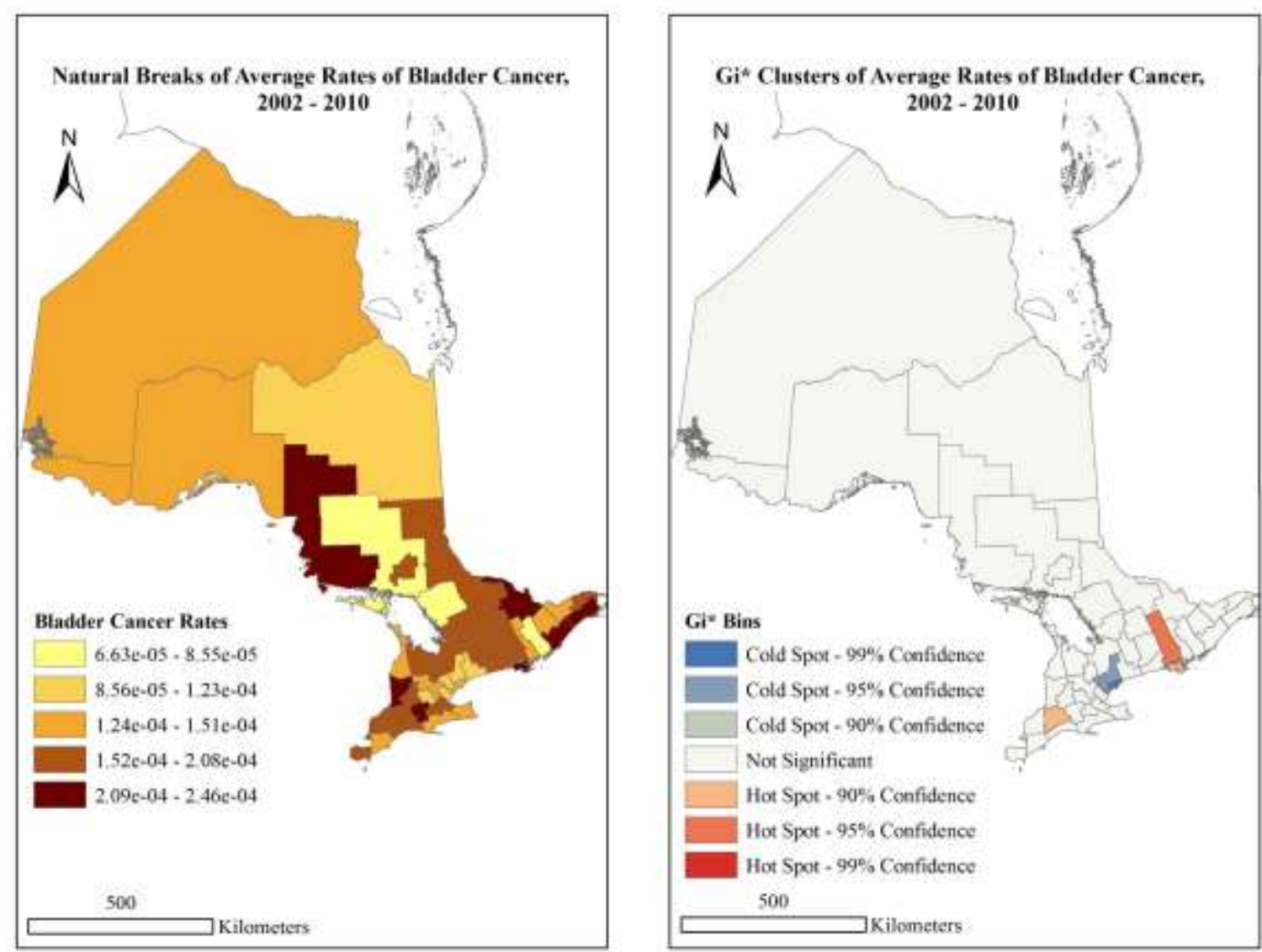

\begin{tabular}{|l|c|c|c|c|}
\hline \multicolumn{5}{|l|}{ Table 1. General G Statistics } \\
\hline Data & Observed G & Expected G & Z Score & p \\
\hline $1991-2001$ & 0.099 & 0.098 & 0.148 & 0.882 \\
\hline $2002-2010$ & 0.096 & 0.098 & -0.765 & 0.445 \\
\hline
\end{tabular}

